\title{
NON-INVASIVE 3D FACIAL ANALYSIS AND SURFACE ELECTROMYOGRAPHY DURING FUNCTIONAL PRE- ORTHODONTIC THERAPY: A PRELIMINARY REPORT
}

\author{
Gianluca M. TARTAGLIA ${ }^{1}$, Gaia GRANDI ${ }^{2}$, Fabrizio MIAN ${ }^{3}$, Chiarella SFORZA ${ }^{4}$, Virgilio F. FERRARIO ${ }^{4}$
}

\begin{abstract}
1- DDS, PhD, Research Associate; Functional Anatomy Research Center (FARC), Laboratorio di Anatomia Funzionale dell'Apparato Stomatognatico (LAFAS), Dipartimento di Morfologia Umana, Facoltà di Medicina e Chirurgia, Università degli Studi, Milano, Italy.

2- DDS, PhD, Research Assistant; Functional Anatomy Research Center (FARC), Laboratorio di Anatomia Funzionale dell'Apparato Stomatognatico (LAFAS), Dipartimento di Morfologia Umana, Facoltà di Medicina e Chirurgia, Università degli Studi, Milano, Italy.

3- DDS, PhD, Private Practice, Milano, Italy.

4- MD, PhD, Professor; Functional Anatomy Research Center (FARC), Laboratorio di Anatomia Funzionale dell'Apparato Stomatognatico (LAFAS),
\end{abstract} Dipartimento di Morfologia Umana, Facoltà di Medicina e Chirurgia, Università degli Studi, Milano, Italy.

Correspondig address: Professor Chiarella Sforza - Department of Human Morphology - University of Milan - via Mangiagalli 31 - Milano, MI I20133 Italy - e-mail: chiarella.sforza@unimi.it - Phone: +39 0250315407 - Fax +3902503 15387

Received: July 06, 2008 - Modification: September 6, 2008 - Accepted: November 09, 2008

\begin{abstract}
Q

bjectives: Functional orthodontic devices can modify oral function thus permitting more adequate growth processes. The assessment of their effects should include both facial morphology and muscle function. This preliminary study investigated whether a preformed functional orthodontic device could induce variations in facial morphology and function along with correction of oral dysfunction in a group of orthodontic patients in the mixed and early permanent dentitions. Material and Methods: The threedimensional coordinates of 50 facial landmarks (forehead, eyes, nose, cheeks, mouth, jaw and ears) were collected in 10 orthodontic male patients aged 8-13 years, and in 89 healthy reference boys of the same age. Soft tissue facial angles, distances, and ratios were computed. Surface electromyography of the masseter and temporalis muscles was performed, and standardized symmetry, muscular torque and activity were calculated. Soft-tissue facial modifications were analyzed non-invasively before and after a 6-month treatment with a functional device. Comparisons were made with z-scores and paired Student's t-tests. Results: The 6-month treatment stimulated mandibular growth in the anterior and inferior directions, with significant variations in three-dimensional facial divergence and facial convexity. The modifications were larger in the patients than in reference children. In several occasions, the discrepancies relative to the norm became not significant after treatment. No significant variations in standardized muscular activity were found. Conclusions: Preliminary results showed that the continuous and correct use of the functional device induced measurable intraoral (dental arches) and extraoral (face) morphological modifications. The device did not modify the functional equilibrium of the masticatory muscles.
\end{abstract}

Key words: Face. Children. Pre-orthodontics. Soft tissues. Electromyography.

\section{INTRODUCTION}

Since its beginning, orthodontic treatment has always focused not only on dental displacement, but also on the control and modification of facial growth ${ }^{7,12,15}$. In growing patients, functional and orthopedic appliances can be used to modify dysfunctional habits, directing the facial structures towards more harmonious relationships ${ }^{6,11-13,15}$.

For instance, in children in the mixed dentition with mildto-moderate mandibular arch perimeter deficiency, continuous lip bumper therapy has been found to significantly modify mandibular incisor inclination, molar position, arch length, arch perimeter ${ }^{1}$, and arch width ${ }^{5}$.
Increments in the maxillary arch width were also reported ${ }^{4}$. Skeletal Class II children treated with a functional device obtained improvements in their dental malocclusion, together with correction of oral dysfunctions ${ }^{6}$. Increments in total facial height and variations in lower incisor proclination were also found ${ }^{15}$.

Among the various functional orthodontic devices, preformed appliances have been proposed to reduce costs and time $e^{6,715}$, thus allowing the interceptive treatment of a larger number of patients in the context of community-based dental services, without the need of specialized dental laboratories ${ }^{6}$. These appliances may allow the treatment of children from low-income families, extending the benefits 
of a global dental care to all society. Previous studies focused on the dentoalveolar modifications induced by these devices, with treatments lasting approximately 1 year ${ }^{6,7,15}$. A polyurethane prefabricated functional appliance, for example, has been shown to induce significant modifications on the transverse and anterior-height dimensions of the maxillary and mandibular dental arches ${ }^{7}$.

Together with variations in dental positions, functional devices can direct soft tissue action ${ }^{12}$, and the evaluation of their efficacy in the modification of dental arch size and shape should also include the quantitative assessment of soft tissue modifications.

Previous studies have investigated the facial morphological modifications induced by functional therapy using cephalometric head films ${ }^{1,6,13,15}$. Unfortunately, the repeated use of $\mathrm{x}$-rays cannot be proposed for growing subjects, considering the biological and physical burden of radiation to the patients. In contrast, the use of non-invasive instruments allows making several, repeated acquisitions thus monitoring the effect of therapy step by step. Also, cephalometric head films cannot be used for a complete assessment of soft tissues, and cannot provide threedimensional data ${ }^{8-10}$. To the best of our knowledge, no previous study has investigated the effects of a preformed functional orthodontic appliance on the three-dimensional characteristics of facial soft tissues.

The present preliminary study investigated whether a preformed functional orthodontic device could induce variations in facial morphology and function along with correction of oral dysfunction in a group of orthodontic patients in the mixed and early permanent dentitions. Softtissue facial modifications were analyzed non-invasively before and after a 6-month treatment. The effect of growth was assessed considering a group of reference children of comparable age. Surface electromyography (EMG) of their masseter (MM) and temporalis anterior (TA) muscles was also performed.

\section{MATERIAL AND METHODS}

\section{Subjects}

Two groups of Caucasian boys aged 8-13 years were analyzed. All boys had no previous craniofacial trauma, surgery or congenital anomalies. Ten boys (mean age 11.2 year, SD 2) were orthodontic patients attending a private practice in Milan, Italy. Eighty-nine boys were healthy, "reference" adolescents, who had average facial dimensions and proportions, according to Italian standards ${ }^{8,9}$. These subjects had had no previous orthodontic treatment, were attending several schools in Milan and the surroundings, and their ages were selected to match those of the orthodontic patients, before and after treatment ${ }^{7,13}$ (Table 1). Their data had been partly published ${ }^{8,9}$.

All children enrolled in the study as well as their parents/ legal guardians gave their informed consent to the experiment. All procedures were non-invasive, did not cause damages, risks or discomfort to the subjects, and were approved by the local Research Ethics Committee.

The orthodontic patients were visited by an orthodontist, and found to need treatment for the correction of an Angle Class II malocclusion. They were either in the mixed or in the early permanent dentition. Most children were oral breathers; dental crowding, excessive overbite and overjet, and deviations of the midline were also found.

A pre-orthodontic functional treatment was devised for all patients, who were given a Pre-Orthodontic Trainer ${ }^{\mathrm{TM}}$ (T4K ${ }^{\mathrm{TM}}$, Myofunctional Research Co., Helensvale, QLD, Australia). This device is a single size, preformed dental silicone positioner. According to the manufacturer, it incorporates myofunctional and tooth positioning characteristics: tooth channels and labial bows guide the erupting/ developing dentition into correct alignment; the tongue tag and lip bumpers treat dysfunctional habits, reducing excessive mentalis muscle activity and tongue thrusting, and forcing a nasal breathing. The children were told to use the device every day for $1 \mathrm{~h}$ plus overnight during sleep. During daytime use, they should close their mouth, breath through the nose, and maximally clench on the device for some

TABLE 1- Orthodontic patients and reference subjects evaluated in the study

\begin{tabular}{|c|c|c|c|c|c|c|}
\hline \multirow[t]{3}{*}{ Patient } & \multirow[t]{3}{*}{ Age $(y ; m)$} & \multirow[t]{3}{*}{ Dentition } & \multicolumn{4}{|c|}{ Reference boys } \\
\hline & & & \multicolumn{2}{|c|}{ Before treatment } & \multicolumn{2}{|c|}{ After treatment } \\
\hline & & & $\mathbf{N}$ & Mean age $(y ; m)$ & $\mathbf{N}$ & Mean age $(y ; m)$ \\
\hline RE & $7 ; 9$ & Mixed & 13 & $7 ; 6$ & 15 & $8 ; 6$ \\
\hline OM & $7 ; 10$ & Mixed & 13 & $7 ; 6$ & 15 & $8 ; 6$ \\
\hline FS & $10 ; 1$ & Mixed & 19 & $10 ; 6$ & 19 & $10 ; 6$ \\
\hline AF & $11 ; 6$ & Permanent & 10 & $11 ; 6$ & 21 & $12 ; 6$ \\
\hline FD & $11 ; 6$ & Mixed & 10 & $11 ; 6$ & 21 & $12 ; 6$ \\
\hline RM & $11 ; 6$ & Permanent & 10 & $11 ; 6$ & 21 & $12 ; 6$ \\
\hline ML & $12 ; 10$ & Permanent & 21 & $12 ; 6$ & 11 & $13 ; 6$ \\
\hline SR & $12 ; 10$ & Permanent & 21 & $12 ; 6$ & 11 & $13 ; 6$ \\
\hline $\mathrm{Al}$ & $13 ; 0$ & Permanent & 21 & $12 ; 6$ & 11 & $13 ; 6$ \\
\hline CA & $13 ; 0$ & Permanent & 21 & $12 ; 6$ & 11 & $13 ; 6$ \\
\hline
\end{tabular}


seconds. The procedure should be repeated intermittently along all the hour.

After the orthodontic assessment, the three-dimensional characteristics of the facial soft tissues of the children were assessed, and a surface EMG of their MM and TA muscles was performed ${ }^{3,10}$.

After 6 months of treatment, the orthodontic patients returned to the laboratory. The clinical assessment was repeated, their faces measured again, and EMG performed.

\section{Three-dimensional characteristics of facial soft tissues: Data collection and analysis}

The same procedure used in previous studies ${ }^{8,9}$ was followed. For each boy, a single experienced operator located and marked 50 soft-tissue landmarks (Figure 1). During landmark marking, the boys sat relaxed with a natural head position. For each boy, this phase lasted less than $5 \mathrm{~min}$.

Three-dimensional coordinates of the facial landmarks were obtained with a computerized electromagnetic digitizer (3Draw, Polhemus Inc, Colchester, VT, USA). During data collection, the children sat in a natural head position in a chair with a backrest, with their head fixed by cephalostat. They remained motionless, with closed eyes and the mandible in rest position. The digitization of landmarks took approximately 1 minute. Duplicate data collections gave random errors corresponding to $1.1 \%$ of nasion-mid tragion distance. Files of the three-dimensional coordinates were obtained, and computer programs were used for all the subsequent off-line calculations.

Landmark coordinates were used to estimate several linear distances, angles, and distance ratios ${ }^{8,9}$ (Table 2).

\section{Surface electromyography: Data collection and analysis}

Left and right MM and TA muscles were examined ${ }^{3,10}$. Disposable silver/ silver chloride bipolar surface electrodes with a diameter of $10 \mathrm{~mm}$ and an interelectrode distance of $21 \pm 1 \mathrm{~mm}$ (Duo-Trode; Myo-Tronics Inc., Seattle, WA, USA) were positioned on the muscular bellies parallel to muscular fibers. A disposable reference electrode was applied to the forehead. EMG activity was recorded using a computerized instrument (Freely, De Götzen srl; Legnano, Milano, Italy), as previously detailed ${ }^{3,10}$. EMG signals were recorded for further analysis.

To standardize the EMG potentials of the four analyzed muscles with tooth contact, two 10-mm thick cotton rolls were positioned on the mandibular first molars of each patient, and a 5-s maximum voluntary clench (MVC) was recorded.

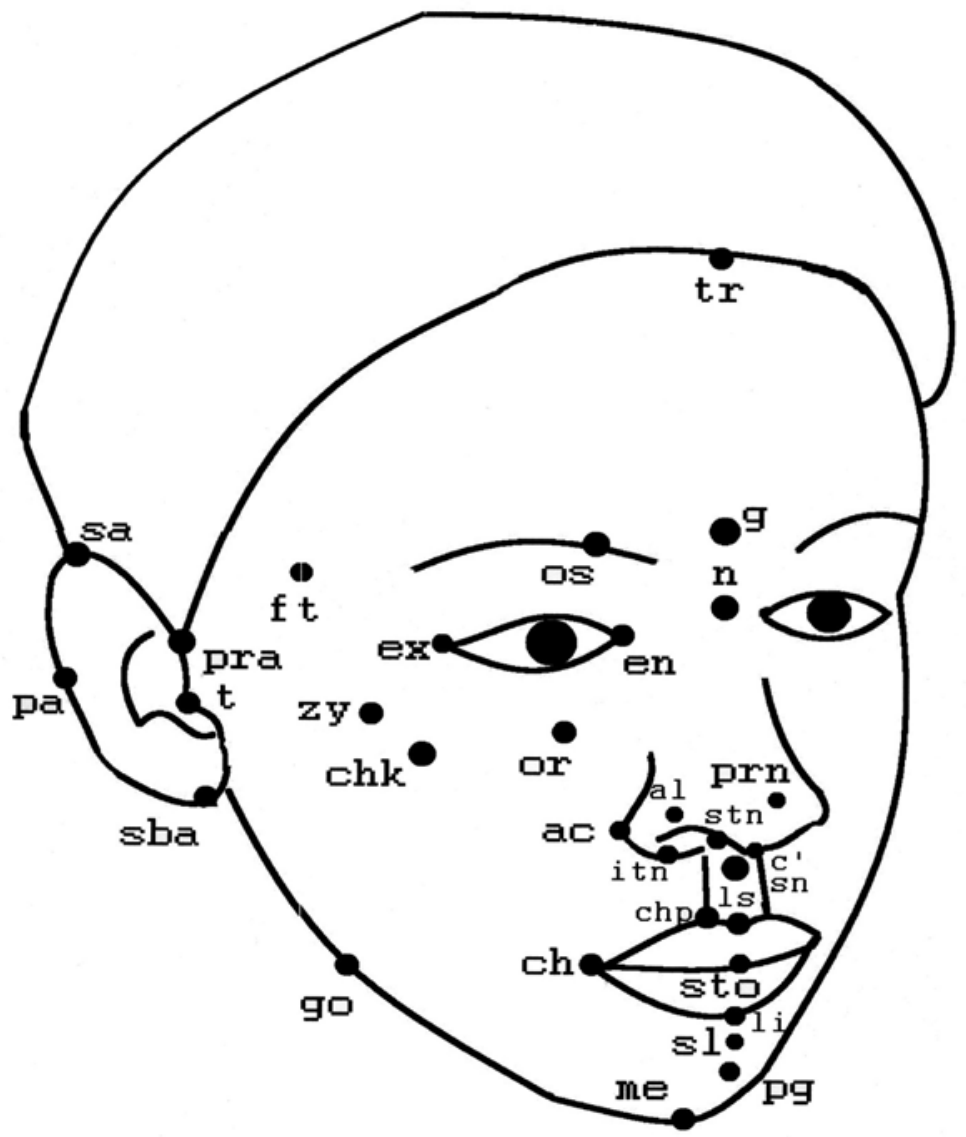

FIGURE 1- Digitized facial landmarks. Midline: tr, trichion; g, glabella; n, nasion; prn, pronasale; c', columella; sn, subnasale; Is, labiale superius; sto, stomion; li, labiale inferius; sl, sublabiale; pg, pogonion; me, menton. Paired: ex, exocanthion ; en, endocanthion; os, orbitale superius; or, orbitale; ft, frontotemporale; chk, cheek ; zy, zygion; t, tragion; al, alare; ac, nasal alar crest; itn, inferior point of the nostril axis; stn, superior point of the nostril axis; chp, crista philtri; ch, cheilion; go, gonion; pra, preaurale; sa, superaurale; pa, postaurale; sba, subaurale 
EMG activity was then recorded during a MVC in intercuspal position; the patient was invited to clench as hard as possible, and to maintain the same level of contraction for $5 \mathrm{~s}$. The test was repeated three times. To avoid any fatigue effects, a rest period of at least 3 min was allowed between standardization recording and tests, as well as between each test. Good reproducibility of surface EMG recordings performed with the same protocol has already been found ${ }^{3}$.

For all tests, the 3-s period with the most stable signal was automatically selected by the software and used for all subsequent computed-assisted analyses. All recordings were obtained without the functional device in the mouth ${ }^{14}$.

For each patient, the EMG potentials of the four analyzed muscles recorded during the MVC tests were expressed as percent of the mean potential recorded during the standardization test (MVC on the cotton rolls), unit: $\mu \mathrm{V} / \mu \mathrm{V}$ $\mathrm{x}$ 100. All subsequent calculations were made with the standardized potentials. The values obtained in the three MVC tests performed by each patient were averaged.

To assess muscle symmetry, the EMG waves of paired muscles of each patient were compared by computing a percentage overlapping coefficient (POC, unit: \%). POC is an index of the symmetric distribution of muscular activity as determined by occlusion. It ranges between 0 (no symmetry) and $100 \%$ (perfect symmetry). MM and TA POCs were obtained for each patient.

Because an unbalanced contractile activity of contralateral MM and TA (e.g., right TA and left MM) might give rise to a potential lateral displacing component, the Torque Coefficient (TC, unit \%) was assessed. TC ranges between $0 \%$ (complete presence of lateral displacing force) to $100 \%$ (absence of lateral displacing force).

To individualize the most prevalent pair of masticatory muscles, the activity index (Ac, unit \%) was computed as the percentage ratio of the difference between the mean $\mathrm{MM}$ and
TA standardized potentials, and the sum of the same standardized potentials. Ac is positive (up to $100 \%$ ) when the MM standardized potentials are larger than the TA ones, negative (up to $-100 \%$ ) when the TA potentials are larger, and null when they are equal.

The mean (MM and TA) total standardized muscle activities (unit: $\mu \mathrm{V} / \mu \mathrm{V} \cdot \mathrm{s} \%$ ) were computed as the integrated areas of the EMG potentials over time.

\section{Statistical calculations}

For each patient, differences between data (facial dimensions, angles and ratios; EMG indices) obtained before and after the 6-month treatment were computed; descriptive statistics obtained, and compared by paired Student's t tests.

For reference boys, mean and standard deviation of the facial dimensions listed in Table 2 were computed for each age.

Patient data were compared to those collected in reference boys of comparable age by computing z-scores. The z-score is a measure of the distance between a subject datum and the reference mean expressed in standard deviation units: z-score $=$ (subject value - mean value of the reference group) divided by the standard deviation of the reference group. Positive $\mathrm{z}-$ scores indicate that the measurement is larger in the subject than in the reference population, while negative z-scores indicate a smaller measurement in the subject than in the reference population; by definition, the reference population has a mean $\mathrm{z}$-score of 0 , with a standard deviation of 1 . For each patient, z-scores were computed before and after treatment using data collected in the reference boys of comparable age.

Z-scores were used because the patients were of different ages: the use of standardized values allowed considering all pre-treatment (or post-treatment) discrepancies as a whole, without further reference to the patient's age.

TABLE 2- Measurements calculated from the digitized landmarks

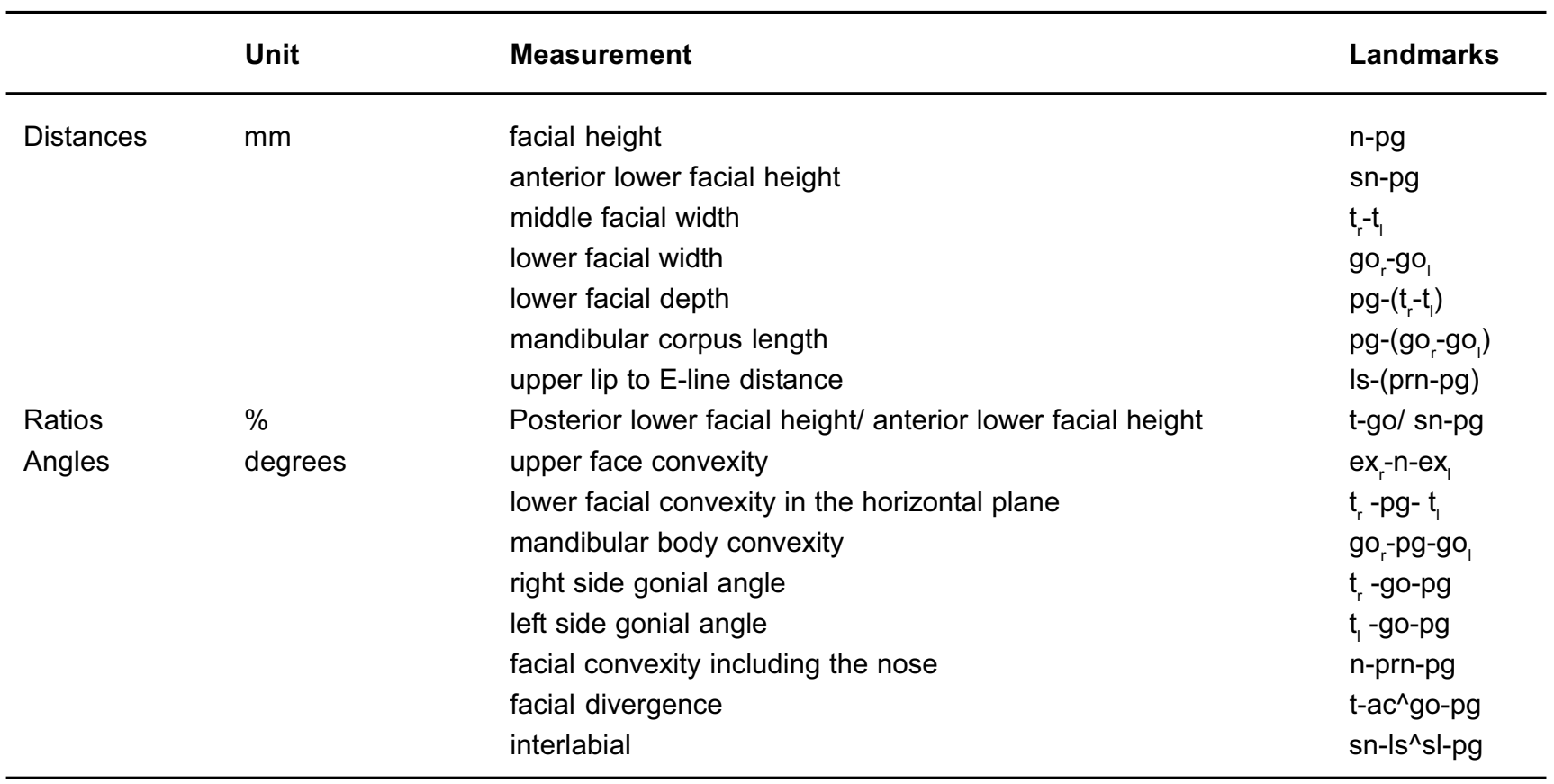


Significance of the z-scores was assessed by the Student's t-tests (if the subject value is equal to the mean value of the reference group, the z-score is zero; the null hypothesis of the test is that the $\mathrm{z}$-scores are null). Significance was set at $5 \%(P<0.05)$.

\section{RESULTS}

Table 3 shows the main clinical modifications recorded in the 10 orthodontic patients between the pre- and posttreatment examinations. In 9 patients, modifications in the midline, reduction of overbite and overjet, reduction of anterior crowding, and a return toward Angle Class I molar and canine relationships were observed. Before treatment, 8 patients were oral breathers; all but one modified their breathing pattern, and obtained a nasal respiration after treatment.

After the 6-month treatment, some significant modifications were found in the dimensions of the facial soft tissues (Table 4). Overall, an increment in anterior facial height (n-pg) was found, with a significant pre-post treatment difference ( $t$ test, $p=0.017$ ). After treatment, the patients were less different from their reference peers (the mean $\mathrm{z}-$ score changed from 0.26 before treatment to -0.097 after treatment). Before treatment, the lower anterior facial height (sn-pg) was significantly larger in the patients than in the reference children, and it normalized after treatment.

Before treatment, the patients had significantly larger middle and lower facial widths than reference children; both values were more similar to the norm after treatment. During the 6-month treatment, significant increments in the anteriorposterior dimension of the lower facial third were found (lower facial depth and mandibular corpus length), with a trend toward a normalization of the upper lip to E-line distance. The posterior lower facial height to anterior lower facial height ratio was significantly reduced before treatment (more than 1 SD smaller than in the reference children); the discrepancy became not significant after treatment. This modification in the t-go/ sn-pg ratio was coupled with a significant reduction in facial divergence (Table 5), with a trend toward a normalization of vertical facial shape.

After treatment, significant variations in the upper face convexity (significantly larger in the patients than in the reference children before treatment, with a return inside normal values after treatment) and in facial convexity including the nose were found. Non-significant reductions in the lower facial convexity in the horizontal plane and in the mandibular body convexity were also found. For both angles, the post-treatment value was nearer to the norm than the relevant pre-treatment value, with $\mathrm{z}$-scores nearer to 0 . A similar trend was observed for both gonial angles, which reduced during treatment becoming similar to the reference values, and for the interlabial angle.

TABLE 3- Modifications of the clinical characteristics of the analyzed orthodontic patients during the 6-month treatment

\begin{tabular}{|c|c|c|c|c|c|c|}
\hline Patient & $\begin{array}{l}\text { Midline } \\
\text { (mm) }\end{array}$ & $\begin{array}{l}\text { Overbite } \\
(\mathrm{mm})\end{array}$ & $\begin{array}{l}\text { Overjet } \\
(\mathrm{mm})\end{array}$ & $\begin{array}{l}\text { Dental } \\
\text { crowding }\end{array}$ & $\begin{array}{l}\text { Dental } \\
\text { Class }\end{array}$ & Notes \\
\hline RE & - & from 6 to 4 & from 4 to 3 & - & - & - \\
\hline OM & - & - & - & 一 & $\begin{array}{l}\text { Right molar: } \\
\text { from }+4 \text { to }+2 \mathrm{~mm} \\
\text { Left molar: } \\
\text { from }+4 \text { to }+2 \mathrm{~mm}\end{array}$ & $\begin{array}{l}\text { From oral to } \\
\text { nasal breathing }\end{array}$ \\
\hline FS & from 2 to 1 & - & - & - & $\begin{array}{l}\text { Left canine: } \\
\text { from }+4 \text { to }+2 \mathrm{~mm}\end{array}$ & $\begin{array}{l}\text { From oral to } \\
\text { nasal breathing }\end{array}$ \\
\hline AF & - & - & - & $\begin{array}{l}\text { Frontal teeth: } \\
\text { reduced }\end{array}$ & 一 & 一 \\
\hline FD & from 2 to 1 & - & - & - & $\begin{array}{l}\text { Right molar: } \\
\text { from }+1 \text { to } 0 \mathrm{~mm} \\
\text { Left canine: } \\
\text { from }+1 \text { to } 0 \mathrm{~mm}\end{array}$ & $\begin{array}{l}\text { From oral to } \\
\text { nasal breathing }\end{array}$ \\
\hline RM & from 2 to 0 & - & - & 一 & $\begin{array}{l}\text { Left molar: } \\
\text { from }+2 \text { to }-1 \mathrm{~mm}\end{array}$ & $\begin{array}{l}\text { From oral to } \\
\text { nasal breathing }\end{array}$ \\
\hline ML & - & - & - & 一- & 一 & $\begin{array}{l}\text { From oral to } \\
\text { nasal breathing }\end{array}$ \\
\hline SR & - & from 4 to 3 & - & 一 & 一 & $\begin{array}{l}\text { From oral to } \\
\text { nasal breathing }\end{array}$ \\
\hline $\mathrm{Al}$ & - & - & from 5 to 4 & $\begin{array}{l}\text { Frontal teeth: } \\
\text { reduced }\end{array}$ & 一 & $\begin{array}{l}\text { Remains oral } \\
\text { breather }\end{array}$ \\
\hline CA & - & from 4 to 3 & from 3 to 2 & 32-33: resolved & - & $\begin{array}{l}\text { Labial incompetence } \\
\text { resolved }\end{array}$ \\
\hline
\end{tabular}


NON INVASIVE 3D FACIAL ANALYSIS AND SURFACE ELECTROMYOGRAPHY DURING FUNCTIONAL PRE-ORTHODONTIC THERAPY: A PRELIMINARY REPORT

TABLE 4- Soft-tissue facial linear distances and ratio measured in 10 orthodontic patients and in 89 reference children

\begin{tabular}{lllllllll}
\hline & n-pg & sn-pg & t-t & go-go & pg-(t-t) & pg-(go-go) & Is-(prn-pg) & t-go/ sn-pg \\
\hline Mean difference & 1.37 & -0.20 & 0.73 & 0.42 & 2.27 & 2.50 & 0.52 & 2.06 \\
SD & 1.48 & 2.05 & 2.15 & 1.08 & 1.44 & 2.85 & 2.71 & 6.70 \\
P (before vs. after) & 0.017 & NS & NS & NS & 0.001 & 0.022 & NS & NS
\end{tabular}

Patients vs. reference

Before treatment

$\begin{array}{lllllllll}\text { Mean z-score } & 0.260 & 0.555 & 0.663 & 0.778 & 0.401 & 0.410 & 0.125 & -1.122 \\ \text { SD } & 0.956 & 0.656 & 0.878 & 0.826 & 0.795 & 0.943 & 0.797 & 1.251 \\ \text { P (significance of z-score) } & \text { NS } & 0.025 & 0.041 & 0.015 & \text { NS } & \text { NS } & \text { NS } & 0.019\end{array}$

After treatment

$\begin{array}{lllllllll}\text { Mean z-score } & -0.097 & 0.083 & 0.453 & 0.536 & 0.282 & 0.738 & 0.008 & -0.854 \\ \text { SD } & 1.082 & 1.204 & 0.963 & 0.796 & 1.127 & 1.222 & 1.056 & 1.303 \\ \text { P (significance of z-score) } & \text { NS } & \text { NS } & \text { NS } & \text { NS } & \text { NS } & \text { NS } & \text { NS } & \text { NS }\end{array}$

Differences are expressed in $\mathrm{mm}$ (distances) and \% (ratio). Patients vs. reference: values are z-score units. $\mathrm{P}$ (before vs. after): probability of a paired Student's t test; null hypothesis: no difference before and after treatment. P (significance of zscore): probability of a paired Student's t test; null hypothesis: the mean z-score is 0 . NS: not significant. $p>0.05$. SD $=$ standard deviation

TABLE 5- Soft-tissue facial angles measured in 10 orthodontic patients and in 89 reference children

\begin{tabular}{|c|c|c|c|c|c|c|c|c|}
\hline & ex-n-ex & $t-p g-t$ & $\begin{array}{l}\text { go-pg } \\
\text {-go }\end{array}$ & $\begin{array}{l}t_{r}-g o \\
-p g\end{array}$ & $\begin{array}{l}t_{1}-g o \\
-p g\end{array}$ & $\begin{array}{l}\text { n-prn } \\
\text {-pg }\end{array}$ & $\begin{array}{l}\text { t-ac^go } \\
-p g\end{array}$ & 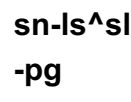 \\
\hline Mean difference & -2.78 & -0.73 & -1.45 & -1.20 & -0.48 & 4.33 & -1.24 & 5.78 \\
\hline SD & 2.37 & 1.17 & 2.11 & 2.81 & 4.12 & 2.61 & 1.61 & 13.75 \\
\hline P (before vs. after) & 0.005 & NS & 0.058 & NS & NS & 0.001 & 0.038 & NS \\
\hline \multicolumn{9}{|l|}{ Patients vs. reference } \\
\hline \multicolumn{9}{|l|}{ Before treatment } \\
\hline Mean z-score & 0.844 & 0.256 & 0.277 & 0.487 & 0.708 & -0.010 & 1.145 & -0.613 \\
\hline SD & 0.995 & 1.143 & 0.716 & 1.455 & 1.201 & 1.142 & 1.712 & 1.123 \\
\hline $\mathrm{P}$ (significance of z-score) & 0.025 & NS & NS & NS & NS & NS & NS & NS \\
\hline \multicolumn{9}{|l|}{ After treatment } \\
\hline Mean z-score & 0.387 & 0.175 & -0.106 & 0.235 & 0.610 & 1.375 & 0.293 & -0.564 \\
\hline SD & 0.796 & 1.326 & 0.855 & 1.330 & 0.892 & 1.828 & 1.585 & 1.555 \\
\hline $\mathrm{P}$ (significance of z-score) & NS & NS & NS & NS & NS & 0.041 & NS & NS \\
\hline
\end{tabular}

Differences are expressed in degrees. Patients vs. reference: values are z-score units. P (before vs. after): probability of a paired Student's t test; null hypothesis: no difference before and after treatment. P (significance of z-score): probability of a paired Student's t test; null hypothesis: the mean z-score is 0 . NS: not significant. $p>0.05$. SD = standard deviation

Both before and after treatment, all EMG indices were comprised inside normal reference values ${ }^{3}$ (Table 6). The Ac index showed a somewhat larger standardized activity of the TA relative to the MM. No significant variations were observed for all analyzed indices. Overall, the good neuromuscular coordination of the masticatory muscles observed before treatment was not modified by the functional appliance. 
TABLE 6- Surface electromyography (EMG) indices obtained in 10 orthodontic patients before and after treatment

\begin{tabular}{|c|c|c|c|c|c|}
\hline & POC TA (\%) & POC MM (\%) & $\mathrm{TC}(\%)$ & Ac (\%) & $\begin{array}{c}\text { Activity } \\
(\mu \mathrm{V} / \mu \mathrm{V} \cdot \mathrm{s} \%)\end{array}$ \\
\hline \multicolumn{6}{|l|}{ Before treatment } \\
\hline Mean & 87.43 & 87.29 & 90.86 & -5.01 & 106.80 \\
\hline SD & 2.19 & 2.67 & 1.85 & 6.84 & 27.05 \\
\hline \multicolumn{6}{|l|}{ After treatment } \\
\hline Mean & 88.18 & 85.84 & 90.76 & -4.76 & 99.6 \\
\hline SD & 1.89 & 4.05 & 2.45 & 12.72 & 24.15 \\
\hline Mean difference & -0.748 & 1.446 & 0.100 & -0.255 & 7.200 \\
\hline SD & 3.07 & 2.541 & 1.865 & 11.464 & 28.217 \\
\hline P (before vs. after) & NS & NS & NS & NS & NS \\
\hline
\end{tabular}

SD: standard deviation; POC: percentage overlapping coefficient (index of left-right muscular symmetry); TC: torque coefficient (potential lateral displacing component); Ac: Activity index (ratio between MM and TA potentials); Activity, unit: pooled muscular activity; $\mathrm{P}$ (before vs. after): probability of a paired Student's t test; null hypothesis: no difference before and after treatment. NS: not significant. $p>0.05$. SD $=$ standard deviation

\section{DISCUSSION}

The functional device used in the present investigation has been reported to stimulate mandibular transverse and anteroposterior growth by a correction of dysfunctional habits: oral breathing, tongue, lips and cheeks trusting, excessive mentalis muscle activity ${ }^{6,715}$. In the present study, almost all of the oral breathers modified their breathing pattern during the treatment, and obtained a nasal respiration, or resolved labial incompetence.

Some previous investigations used the same functional device that we used, and focused on the dentoalveolar modifications induced by the device, with treatments lasting approximately 1 year ${ }^{6,7,15}$.

In a pilot investigation, Quadrelli, et al. ${ }^{6}$ treated six skeletal Class II children, with improvements in the dental malocclusion. Ramirez-Yañez, et al. ${ }^{7}$, in a wider study performed on 60 patients, found significant increments in transverse arch dimensions, as well as in the height of anterior maxillary arch. After 13 months of treatment, Usumez, et al. ${ }^{15}$ found significant increments in total facial height, and reductions in overjet. In contrast, no data were reported on the modifications induced on the facial soft tissues.

Overall, soft-tissue data found in the current investigation were in good accord with previous hard-tissue data: the 6month treatment significantly stimulated mandibular growth in the anterior [pg-(t-t), pg-(go-go)] and inferior (n-pg) directions, with significant variations in facial divergence (t-ac^go-pg) and facial convexity (ex-n-ex; go-pg-go; n-prn$\mathrm{pg}$ ). At the same time, some clinically positive modifications were found in the relative position of anterior (crowding, overbite, overjet) and posterior (dental class) teeth.

Facial data collected in the orthodontic patients were compared to those obtained in healthy reference children ${ }^{8,9}$. Patient data were used to determine age at the beginning and at the end of treatment, and were matched with normative data with respect to age and $\operatorname{sex}^{7,13}$. Indeed, when analyzing growing subjects, it is necessary to distinguish between the effect of treatment and that of normal growth and development ${ }^{4,5,13}$. Patients were compared to normal children using z-scores, and the discrepancies between patients and reference children of comparable age were analyzed both before and after treatment. Some significant differences relative to the norm that were found before treatment normalized (became not significant) after treatment (ex-nex; sn-pg; t-t; go-go; t-go/ sn-pg). Overall, these 6-month modifications seemed larger in the patients than in the reference children.

After the use of a different myofunctional appliance on children aged 7-12, similar effects (modifications larger than normal range of variation) were reported also by Tallgren, et al. ${ }^{13}$ for hard-tissue anterior facial height and length of mandibular base. Of course, even the most detailed analysis of facial soft tissues cannot substitute the radiographic assessment of dental arches and head skeleton. Nevertheless, non-invasive soft-tissue assessments can be coupled with radiographic films, allowing three-dimensional measurements that can be repeated during treatment to monitor the effect of therapy step by step ${ }^{10}$. Another useful, additional examination can be surface EMG of the masticatory and facial muscles ${ }^{2,6,10-14}$.

Previous studies reported some EMG data after treatment with functional devices. Quadrelli, et al. ${ }^{6}$ found positive modifications in the electrical activity of masticatory muscles. Tallgren, et al. ${ }^{13}$ reported a decrease in orofacial muscle activity during oral function. In the present study, to assess the neuromuscular coordination of the masticatory 
muscles, only standardized EMG indices were obtained ${ }^{3}$. All patients had standardized EMG indices inside normal ranges both before and after treatment. The good neuromuscular equilibrium observed before treatment was not modified by the functional appliance: orthodontic stability has already been reported to depend from a wellbalanced muscular activity ${ }^{2,11}$. Current data cannot be directly compared to those reported in previous studies because we did not assess single EMG potentials but only the global neuromuscular equilibrium ${ }^{2,3,11}$. The use of standardized EMG data is necessary considering the inherent variability in surface EMG potentials ${ }^{2,3,11}$.

Overall, the current clinical, functional and morphological results were obtained with a period of treatment shorter than those previously reported in literature ${ }^{4-}$ $7,13,15$, indicating an immediate positive effect of the functional device. A similar finding was previously reported for arch width expansion: most of the effect is obtained in the first period of treatment ${ }^{5}$. Therefore, the current device could be proposed also for a short-term interceptive treatment, modifying the dysfunctional habits and permitting the best subsequent orthodontic and orthopedic intervention. One of the advantages of the device is its single size: the use of a preformed device can reduce costs and time, thus allowing the treatment of a larger number of children in a communitybased dental service ${ }^{6}$.

One of the limitations of the use of functional appliances is patient's compliance. Indeed, several EMG studies found that orthodontic functional appliances should be used during both sleep and daytime in combination with voluntary clenching to achieve the best adaptation and development of the masticatory muscles ${ }^{12,13}$. The muscles should adapt to the new mandibular position given by the appliance, and only a constant use will give actual modifications in the dental, skeletal and soft-tissue structures ${ }^{12}$. In the present study, the patients were given a notebook where they wrote down the use of the device: overall, they seemed to have been used it for all the necessary time. Unfortunately, their records cannot be verified, and only the effects induced on their faces and dental arches can be observed.

\section{CONCLUSIONS}

In 10 orthodontic male patients aged 8 to 13 years, a 6month treatment with a single size, preformed dental silicone positioner obtained: 1 . significant mandibular growth in the anterior and inferior directions; 2 . significant variations in facial divergence and facial convexity; 3 . no modifications in the functional equilibrium of the masticatory muscles.

\section{REFERENCES}

1- Davidovitch M, McInnis D, Lindauer SJ. The effects of lip bumper therapy in the mixed dentition. Am J Orthod Dentofacial Orthop. 1997; 111:52-8.

2- Ferrario VF, Marciandi PV, Tartaglia GM, Dellavia C, Sforza C. Neuromuscular evaluation of post-orthodontic stability: an experimental protocol. Int J Adult Orthodon Orthognath Surg. 2002;17:307-13.

3- Ferrario VF, Tartaglia GM, Galletta A, Grassi GP, Sforza C. The influence of occlusion on jaw and neck muscle activity: a surface EMG study in healthy young adults. J Oral Rehabil. 2006;33:341-8.

4- Häsler R, Ingervall B. The effect of a maxillary lip bumper on tooth positions. Eur J Orthod. 2000;22:25-32.

5- Moin K, Bishara SE. An evaluation of buccal shield treatment: a clinical and cephalometric study. Angle Orthod. 2007;77:57-63.

6- Quadrelli C, Gheorgiu M, Marchetti C, Ghiglione V. Early myofunctional approach to skeletal Class II. Mondo Ortod. 2002;27:10922 .

7- Ramirez-Yañez G, Sidlauskas A, Junior E, Fluter J. Dimensional changes in dental arches after treatment with a prefabricated functional appliance. J Clin Pediatr Dent. 2007;31:279-83.

8- Sforza C, Laino A, D’Alessio R, Dellavia C, Grandi G, Ferrario VF. Three-dimensional facial morphometry of attractive children and normal children in the deciduous and early mixed dentition. Angle Orthod. 2007;77:1025-33.

9- Sforza C, Laino A, D’Alessio R, Grandi G, Tartaglia GM, Ferrario VF. Soft-tissue facial characteristics of attractive and normal adolescent boys and girls. Angle Orthod. 2008;78:799-807.

10- Sforza C, Peretta R, Grandi G, Ferronato G, Ferrario VF. Soft tissue facial planes and masticatory muscle function in skeletal Class III patients before and after orthognathic surgery treatment. J Oral Maxillofac Surg. 2008;66:691-8

11- Souza DR, Semeghini TA, Kroll LB, Berzin F. Oral myofunctional and electromyographic evaluation of the orbicularis oris and mentalis muscles in patients with class II/1 malocclusion submitted to first premolar extraction. J Appl Oral Sci. 2008;16:226-31.

12- Tabe H, Ueda HM, Kato M, Nagaoka K, Nakashima Y, Matsumoto E, et al. Influence of functional appliances on masticatory muscle activity. Angle Orthod. 2005;75:616-24.

13- Tallgren A, Christiansen RL, Ash M Jr, Miller RL. Effects of a myofunctional appliance on orofacial muscle activity and structures. Angle Orthod. 1998;68:249-58.

14- Tecco S, Epifania E, Festa F. An electromyographic evaluation of bilateral symmetry of masticatory, neck and trunk muscles activity in patients wearing a positioner. J Oral Rehabil. 2008;35:433-9.

15- Usumez S, Uysal T, Sari Z, Basciftci FA, Karaman AI, Guray E. The effects of early preorthodontic trainer treatment on Class II, division 1 patients. Angle Orthod. 2004;74:605-9.

\section{ACKNOWLEDGEMENTS}

The expert secretarial assistance of Ms. Cinzia Lozio is gratefully acknowledged. We are also grateful to all the children and families who participated in the study. 